\title{
Mark Blaug on the normativity of welfare economics
}

\author{
D. WADE HANDS \\ University of Puget Sound
}

\begin{abstract}
This article examines Mark Blaug's position on the normative character of Paretian welfare economics in general, and also specifically with respect to his debate with Pieter Hennipman over this question during the 1990s. The article also clarifies some of the confusions that emerged within the context of this debate, and provides as a conclusion some additional arguments supporting Mark Blaug's position, which he himself did not provide.
\end{abstract}

Keywords: positive and normative economics, Pareto optimality, welfare economics, ethical and methodological norms, Blaug-Hennipman debate

JEL Classification: A13, B21, B31, B41, D60

Without norms, normative statements are impossible. At some point welfare economics must introduce ethical welfare functions from outside of economics. Which set of ends is relevant is decidedly not a scientific question of economics (Samuelson 1952, 1103).

In welfare economics one is engaged in ethical counseling on the economic aspects of social states (Bergson 1954, 247).

In short, there is no such thing as "value-free welfare economics" and, indeed, the phrase itself is a contradiction in terms. To say that something is an improvement in "welfare" is to say that it is desirable, and persuasive statements of this kind necessarily involve ethical considerations (Blaug 1978, 626).

This article will re-examine Mark Blaug's position on the normative character of Paretian welfare economics. Section one explains Blaug's position and its relationship to the views of the founders of the new welfare economics in the 1930s and 1940s. Section two examines

AUTHOR's NoTE: I would like to thank John Davis and two anonymous reviewers for helpful comments on earlier versions of this article. 
Blaug's argument in more detail through the lens of his debate with Pieter Hennipman (Blaug 1993; Hennipman 1992, 1993): a (sometimes rather heated) exchange in which Hennipman argued that Paretian welfare economics was (or at least could be) strictly positive economic science, while Blaug argued it was inescapably normative. Providing an overall assessment of the debate will prove to be impossible, because the authors were often talking at cross-purposes and defining key terms in very different ways. However, it is still possible to better understand the two positions and to identify the relationship between the presuppositions of the two economists and their stance on the normativity question.

After the examination of Blaug's position in the first two sections, the last section turns to clarifying some sources of the miscommunication in the Hennipman-Blaug exchange as well as to suggest some additional arguments that Blaug might have made in his response to Hennipman and to other defenders of the strictly positive interpretation of new welfare economics. The three main goals of the paper are 1) to clarify Blaug's normative reading of Paretian welfare economics and situate his arguments within the broader literature on the ethical and methodological foundations of welfare economics, 2) to identify some of the origins of the communication problems apparent in the Blaug-Hennipman debate, and 3) to try to add some additional arguments supporting Blaug's interpretation that he himself did not provide.

\section{BLAUG ON POSITIVE AND NORMATIVE IN THE NEW WELFARE ECONOMICS}

Blaug's argument for the normativity of welfare economics was presented in two of his most popular books: his history of economic thought textbook Economic theory in retrospect (1987 [1962]), and his survey of economic methodology The methodology of economics (1992 [1980]). His arguments were repeated and expanded in various places (1987 [1962]; 1990a; 1998) and he was also the author of an important historical paper on the first and second fundamental theorems of welfare economics (2007). His basic position remained the same in all of this follow-up literature: i) Paretian welfare economics is necessarily normative; ii) contra Lionel Robbins and others, its normativity does not prevent the legitimate use of welfare analysis in economic science; and yet 3) it is important to maintain "the positivenormative distinction as far as it can be maintained” (Blaug 1998, 373). 
Before delving into the details of Blaug's position, it seems useful to review the history of the new welfare economics. Welfare economics has traditionally been defined as the (micro)economic theory that provides tools for the evaluation of various economic policies, institutional arrangements, and allocations of economic resources (outcomes). Since throughout the history of economics the most carefully analyzed institution for the allocation of resources has been the competitive market, there has always been a close connection between welfare economics and the idea that "in some sense perfect competition represented an optimal situation" (Samuelson 1947, 203).

Focusing on mainstream post-classical views, welfare economics experienced two periods of relatively stable equilibria: the "old" hedonistic-utilitarian welfare economics of the early neoclassicals and turn-of-the-century British economists like Alfred Marshall and Arthur C. Pigou, and the "new" welfare economics associated originally with Vilfredo Pareto, but formalized and stabilized by economists such as Abram Bergson, Oscar Lange, and Paul Samuelson during the period 1935-1955. Lionel Robbins's influential An essay on the nature and significance of economic science (1935 [1932]) did not make a direct contribution to the new welfare economics, but his critique of the older approach set the stage for the new theory by arguing persuasively against the possibility of making purely scientific interpersonal utility comparisons. ${ }^{1}$ This change in welfare economics was of course associated with the ordinal revolution, the move from cardinal to ordinal utility within consumer choice theory during the 1930s. ${ }^{2}$

One of the key organizing principles of the new welfare economics was of course the concept of a Pareto optimal (PO), or economically efficient, allocation of resources: an allocation from which it is impossible to make one person better off without making someone else worse off. Since the possibility of making one person better off

\footnotetext{
${ }^{1}$ Key foundational texts for the new welfare economics include: Bergson 1938; Lange 1942; and Samuelson 1947, chapter 8. However, the ideas were popularized in a number of books originally published during the immediate post-World-War-II period such as: Graaff 1968 [1957]; Little 2002 [1950]; and Myint 1965 [1948]. Samuelson provided a definitive summary statement of Bergsonian welfare economics many years later, see Samuelson 1981.

2 Although the exact relationship is much more complex and tension-laden than generally recognized: tensions clearly exhibited in the debate surrounding the Robert Cooter and Peter Rappoport paper on this topic during the mid-1980s. See Cooter and Rappoport 1984, and 1985; Davis 1990; Hennipman 1987; Little 1985. For discussions of the historical and philosophical complexities of the ordinal revolution, see Hands 2009 , and 2010.
} 
without making someone else worse off implies the existence of a potential Pareto improvement (PPI), a PO allocation is thus one from which there exists no PPIs. In the new welfare economics the relevant vehicle for the evaluation of whether an allocation is "better" or "worse" for a particular individual is his/her ordinal utility function (or the associated well-ordered preferences) from modern demand theory. The two main theoretical results of the new welfare economics were the first and second fundamental theorems which linked the concept of a PO allocation to the Walrasian competitive equilibrium (CE). The first fundamental theorem states that every CE is PO: that a CE is sufficient for an efficient allocation of resources. The second fundamental theorem states that any PO allocation of resources can be achieved by a combination of $\mathrm{CE}$ and some set of lump-sum transfers (taxes and/or subsidies). ${ }^{3}$

Although the first and second fundamental theorems demonstrate the relationship between $\mathrm{CE}$ and $\mathrm{OP}$ allocations, they do not alone answer the traditional question about the socially optimal allocation of resources or the associated institutions or policies. The problem is the non-uniqueness of efficient allocations. Even in a simple two-good two-agent pure exchange model there are an infinite number of PO allocations (given by the contract curve). Yes, each could be supported by some CE price vector, and yes, every CE price vector is associated with one of these efficient allocations, but that does not alone identify the socially optimal allocation. For that, the new welfare economics employed Bergson's idea of a social welfare function (SWF): a function that assigns a level of welfare (W) to each of the relevant states of the world based on the social/ethical values of the relevant society. ${ }^{4}$ In its most general form, SWF is given by:

\footnotetext{
${ }^{3}$ For a detailed history, see Blaug 2007. For a detailed discussion of the philosophical foundations of these two theorems, see Hausman and McPherson 2006.

${ }^{4}$ The importance of Bergson's contribution to the new welfare economics is captured nicely in a quote from Samuelson $(1981,3)$ :

As I write, the new welfare economics is just over four decades old. This subject, in its essentials as we know it today, was born when the 24-year-old Abram Bergson-then still a Harvard graduate student-wrote his classic 1938 Quarterly Journal of Economics article. To one like myself, who before 1938 knew all the relevant literature on welfare economics and just could not make coherent sense of it, Bergson's work came like a flash of lightning, describable only in the words of the pontifical poet:
}

Nature and Nature's laws lay hid in night:

God said, Let Newton be! and all was light. 


$$
\mathrm{W}=\omega\left(\mathrm{x}^{1}, \mathrm{x}^{2}, \ldots, \mathrm{x}^{\mathrm{N}}\right)
$$

where the xis are various states of the world. ${ }^{5}$ Although the most general form of the SWF in (1) is the conceptual starting point, most work in the new welfare economics was based on the more restricted case of an individualistic social welfare function: one that "respects" individual valuations. Given the standard characterization of individual ' $i$ '-his/her ordinal utility function $\mathrm{U}^{\mathrm{i}}\left(\mathrm{x}^{\mathrm{i}}\right)$ - the individualistic social welfare function becomes;

$$
\mathrm{W}=\mathrm{w}\left[\mathrm{U}^{1}\left(\mathrm{x}^{1}\right), \mathrm{U}^{2}\left(\mathrm{x}^{2}\right), \ldots, \mathrm{U}^{\mathrm{J}}\left(\mathrm{x}^{\mathrm{J}}\right)\right] \text { with } \partial \mathrm{w} / \partial \mathrm{U}^{\mathrm{i}}>0 \text { for all } \mathrm{i},
$$

where each $\mathrm{U}^{\mathrm{i}}$ is well-behaved and exhibits neither envy nor altruism. This is the form of the social welfare function that has been most discussed in the literature over the years, in part because it corresponds with how most economists think about individual agents and in part because it captures the profession's (individualistic) intuitions regarding what ought to count within welfare economics, but also because it facilitates the derivation of necessary conditions for social welfare maximization in terms of Pareto optimality: "as a criterion for a maximum position the condition that it should be impossible in this position to increase the welfare of one individual without decreasing that of another" (Bergson 1938, 326). Notice that such a social welfare function will necessarily make (ordinal) interpersonal utility comparisons; it is the ability to make such comparisons that allows maximization of the SWF to identify the social optimal (identify the optimal allocation among the infinite number of PO allocations along the contract curve). As Samuelson explained:

[...] we have seen that it is not possible to deduce a unique equilibrium unless we have more to build upon. This is only as it should be, for intuition assures us that there cannot be an optimum position which is independent of the exact form of the $\mathrm{W}$ function [...] Without a well-defined $\mathrm{W}$ function, i.e., without assumptions concerning interpersonal comparisons of utility, it is impossible to decide which of these points is best. In terms of a given set of ethical notions which define a Welfare function the best point on the generalized contract locus can be determined, and only then (Samuelson 1947, 243-244).

\footnotetext{
${ }^{5}$ I employ the compact symbolism employed in Samuelson 1977.
} 
Of course it is always possible to move beyond the general individualistic SWF in (2) to a third level of welfare concretization, to obtain specific results based on the value judgments of a particular society or group of individuals. This could be done by specifying either more restrictive functional forms or explicit functions for the $\mathrm{w}(\cdot)$ as well as each of the $\mathrm{U}^{\mathrm{i}}(\cdot) \mathrm{s}$ and solving the maximum conditions for that particular case. For example, if one takes $\mathrm{w}(\cdot)$ to be additively separable and takes each $\mathrm{U}^{\mathrm{i}}(\cdot)$ to be a cardinal indicator of each individual's hedonistic utility, one would have the traditional utilitarian social utility function associated with Bentham and the early British neoclassicals.

In this way, Samuelson and others argued that the new welfare economics provided a general framework for welfare analysis that was not dependent on any specific set of ethical commitments, while at the same time accommodating the various ethical views present in the previous literature as particular instantiations of the general analytical framework. It should be noted that this is all quite consistent with the general approach to economic analysis presented in Part I of Samuelson's Foundations (1947): characterize the economic problem in terms of a constrained optimization problem, put enough additional structure on the relevant functions to obtain first order conditions for the general problem, and finally move to explicit functions or functional forms to get specific results for particular applications (in this case for particular ethical values). Also notice that when specific value judgments are included, they are the value judgments of the relevant social community or decision maker. The argument that taking the value judgments of the relevant community as data or background information is scientifically just fine-even though injecting your own value judgments into the analysis is not-goes back to at least Max Weber and was consistently endorsed by Robbins and others (see Mongin 2006, 276). As Bergson explained in his original paper:

In general, any set of value propositions which is sufficient for the evaluation of all alternatives may be introduced, and for each of these sets of propositions there corresponds a maximum position. The number of sets is infinite, and in any particular case the selection of one of them must be determined by its compatibility with the values prevailing in the community the welfare of which is being studied. For only if the welfare principles are based upon prevailing values, can they be relevant to the activity of the community in question (Bergson 1938, 328). 
So given all this, what was scientific/positive and what was normative/ethical within the new welfare economics according to its founders like Bergson and Samuelson? Obviously, the social welfare function is explicitly ethical ${ }^{6}$-its purpose is to make interpersonal welfare judgments-but that did not mean that welfare economics was not a legitimate part of economic analysis. The argument was that this is no different than what is regularly done in other areas of economic analysis such as consumer choice theory. The economist takes the "tastes" (the utility function) of the consumer as given and these tastes reflect "values", but they are the values of the consumer and not necessarily the values of the economic analyst. As Samuelson put it in Foundations:

It is a legitimate exercise of economic analysis to examine the consequences of various value judgments, whether or not they are shared by the theorist, just as the study of comparative ethics is itself a science like any other branch of anthropology. If it is appropriate for the economist to analyze the way Robinson Crusoe directs production so as to maximize his (curious) preferences, the economist does not thereby commit himself to those tastes or inquire concerning the manner in which they were or ought to have been formed (Samuelson 1947, 220).

For Samuelson, the fact that welfare economics-at least welfare economics that employs a SWF-involves value judgments does not prevent it from being a legitimate part of economic analysis, but it does mean that that the results produced by welfare economics are not empirically "meaningful" in the positivistic sense employed throughout Foundations. As he says:

It is only fair to point out, however, that the theorems enunciated under the heading of welfare economics are not meaningful propositions or hypotheses in the technical sense. For they represent the deductive implications of assumptions which are not themselves meaningful refutable hypotheses about reality (Samuelson 1947, 220-221).

Again, this is entirely consistent with the analytical framework of Foundations: the mathematical machinery facilitates economic

\footnotetext{
${ }^{6}$ As Samuelson put it, the SWF "is supposed to characterize some ethical belief-that of a benevolent despot, or a complete egotist, or 'all men of good will', a misanthrope, a state, race, or group mind, God, etc." (Samuelson 1947, 221).
} 
analysis-deductions and theorems from various assumptions-but the cognitive status of the theorems so deduced, whether they are empirically meaningful or not, depends on the empirical content of the underlying assumptions: "By a meaningful theorem I mean simply a hypothesis about empirical data which could conceivably be refuted, if only under ideal conditions" (Samuelson 1947, 4). The new welfare economics involving a SWF is valid and useful economic analysis, although not strictly positive economic science under Samuelson's definition of empirical science.

It is difficult to compare Blaug's argument that welfare economics necessarily involves value judgments (discussed below) with the role that Bergson and Samuelson assign to value judgments in the new welfare economics. The problem is that Blaug and the founders of the new welfare economics focus on different parts of the theory. For Bergson and Samuelson welfare economics necessarily requires interpersonal utility comparisons, and therefore a SWF, and that is where the ethics enters into the analysis. In other words, what makes a particular piece of economic analysis "welfare economics" is the social welfare function and the question of whether the new welfare economics involves value judgments reduces to the question of the cognitive status of the social welfare function itself; Bergson and Samuelson were relatively silent about the cognitive status of the various parts of economic theory involved in welfare economics other than (or prior to) the SWF, such as the concept of a Pareto optimal/efficient allocation, the contract curve, and the associated fundamental theorems. Implicitly it seems they considered the cognitive status of such concepts to be the same as that of consumer choice theory and the other parts of economic analysis that new welfare economics is associated with, but these parts of economic theory raise much more general methodological questions than the question of value judgments specific to the new welfare economics.

This is not the case for Blaug. In fact Blaug has very little to say about the SWF. For Blaug, welfare economics is the use of Pareto optimality and the associated fundamental theorems to analyze various questions about economic institutions and microeconomic policy, and that often has nothing to do with a SWF, but rather involves the direct application of PO, PPI, and the fundamental theorems. After Bergson and Samuelson, most economists agreed that SWF-based welfare economics was normative and necessarily involved value judgments, 
but for Blaug that was not the important methodological question. The important methodological issue for Blaug was the cognitive status of the concept of Pareto optimality itself, and by implication, the parts of welfare economics such as the first and second fundamental theorems that were based on Pareto optimality. This was a part of the new welfare economics that most mainstream economists, following Pareto, considered to be positive economics and devoid of any value judgments. As Blaug explains:

Pareto asserted, in his now famous statement of the conditions of optimality, that perfect competition would automatically maximize collective ophelimity [...] in the sense that no reallocation of resources could make anyone better off without at least making one person worse off. As far as he was concerned, this was a proposition of pure economics, which was completely independent of any ethical value judgments (Blaug 1992 [1980], 122).

It was this aspect of Paretian welfare economics, the concept of efficiency and the associated fundamental theorems-"the quaint notion of the 'new' welfare economics that propositions about 'efficiency' are somehow value-free, while propositions about 'equity' are necessarily value laden" (Blaug 1978, 626) - that concerned Blaug, not the SWF that housed the normativity for Bergson and Samuelson.

Blaug made a multi-pronged attack on the claim that the Paretian welfare economics of the first and second fundamental theorems was, or could reasonably be made into, strictly positive economic science. Perhaps his most direct argument was that the concept of Pareto optimality itself involved value judgments. He noted three separate ways in which the Paretian concept of efficiency is value-laden.

[...] the concept of a Pareto-optimal allocation of resources is predicated on three assumptions which are undeniably judgments of values: (1) that every individual is the best judge of his own welfare; (2) that the social welfare is defined only in terms of the welfare of individuals; and (3) that the welfare of individuals may not be compared (Blaug 1978, 626).

Blaug's interpretation of statements (1) and (2) seems to be correct as long as one identifies a socially optimal allocation with a socially desirable (or, even more ethics-laden "good") allocation. The statement that a more desirable allocation of resources is one with more welfare as judged by the relevant individuals and only the relevant individuals 
clearly involves value judgments. The presumption that efficiency is (perhaps even ethically) desirable is certainly suggested by the profession's traditional rhetoric - an allocation where one person cannot be made better off without making someone else worse off is called "efficient", not "horrible" or some other term with a negative connotation-but as we will see in the next section, not everyone involved in the debate surrounding the new welfare economics would attach such meaning to efficiency. On the other hand, (3) might be considered an empirical statement-for example, if utility is a mental state measurable by modern neurophysiological scanning techniques then it might be empirically testable-but it could also be a value judgment, although not an ethical value judgment. As discussed below, Blaug himself, following Ernest Nagel, makes a distinction between methodological judgments and (ethical) value judgments (Blaug 1992 [1980], 114), and (3) seems to clearly be a judgment about the methodological limitations of our scientific tools, not an ethical judgment.

The second of Blaug's arguments stems from his understanding of philosophy of science as a normative enterprise. Economists, following Robbins (1935 [1932]), Milton Friedman (1953), and others, have traditionally equated "normative" with "ethical"-equating what "ought to be" with what "ought to be on moral grounds"-and while ethical normativity is one kind of normativity, it is certainly not the only kind. Norms involve rules and action-guiding principles; they are prescriptive, but not all prescriptions prescribe that which is moral. Philosophy of natural science has traditionally been a normative discipline specifying what scientists ought to do in order to be good scientists (to find truth, or to save the phenomena, or to uncover the hidden causal forces, or what have you), so when Blaug the economic methodologist says that economists should make bold conjectures and subject them to severe empirical tests, he is making a normative claim. This understanding of the tight connection between scientific practice (what "is" in science) and methodological norms (what scientists "ought" to do) has often led Blaug to talk down the strict dichotomy between positive and normative that economists have long endorsed (if not always practiced) and this in turn adds another pathway for value judgments to enter into welfare economics. ${ }^{7}$ Since "Science as a social enterprise cannot

\footnotetext{
${ }^{7}$ For a general discussion of the positive-normative dichotomy in economics, see Hands 2012a.
} 
function without methodological judgments" (Blaug 1992 [1980], 114) methodological value judgments like (3) above are bound to be involved in even the most scientific welfare economics. Of course, this is an argument that is not restricted to the new welfare economics, or even welfare economics in general; it applies to all economic (and all other) science. $^{8}$

Blaug also makes several arguments for an even broader interaction between positive/facts and normative/values in welfare (and other) economics. The facts of the matter often have an important impact on our moral (and other) normative evaluations and thus these normative appraisals may be much more amenable to rational criticism and reasoned revision than traditionally supposed. If so, the concept of economic efficiency could involve value judgments, even moral value judgments, and yet be subject to scrutiny and revision by reason and evidence. As Blaug explains:

We have overstated the case in suggesting that normative judgments are the sort of judgments that are never amenable to rational discussion designed to reconcile whatever differences there are between people. Even if Hume is right in denying that "ought" can be logically deduced from "is", and of course "is" from "ought", there is no denying that "oughts" are powerfully influenced by "ises" and that the values we hold almost always depend on a whole series of factual beliefs (Blaug 1992 [1980], 115).

Although Blaug's various points do not come together to produce a single knock-down argument for the normativity of the new welfare economics, taken in total they add up to a fairly serious indictment of the view that the new welfare economics, at least sans the SWF, is just one of many cognitively equivalent subfields within positive economic science and involves no value judgments. As Blaug summarized his view:

The concept of Pareto optimality and the associated concept of PPIs, should not be confused with the theorems of positive economics. If this implies that economists must give up the notion that there are purely technical, value-free efficiency arguments for certain

\footnotetext{
${ }^{8}$ As I pointed out many years ago (Hands 1984), Blaug's appreciation of the interaction between methodology and the actual historical practice of science was not always apparent in either his methodological writings or in his work in the history of economic thought. See, for example, our exchange on Blaug's interpretation of the Keynesian revolution: Blaug 1976, 1990a, 1991; and Hands 1990.
} 
economic changes, and indeed that the very terms "efficient" and "inefficient" are terms of normative and not positive economics, so much the better: immense confusion has been sown by the pretense that we can pronounce "scientifically" on matters of "efficiency" without committing ourselves to any value judgments (Blaug 1992 [1980], 127).

\section{BLAUG-HENNIPMAN DEBATE ON THE NORMATIVITY OF NEW WELFARE ECONOMICS}

This section will discuss the Blaug versus Hennipman exchange over the normativity of the new welfare economics during the early 1990s. Although the arguments involved in that exchange will be the main focus, the discussion starts a few decades earlier with a paper on welfare economics by G. C. (Chris) Archibald published in 1959. The views expressed in the Archibald paper are frequently repeated by Hennipman-in fact Blaug refers to "the Archibald-Hennipman argument" (Blaug 1992 [1980], 126) - but that is not the only reason for examining Archibald's paper. In addition, Archibald's interpretation of the new welfare economics has a special significance because he, like Blaug, was attempting to formulate an interpretation of modern economics (including welfare economics) consistent with Karl Popper's philosophy of science. This Popperian connection puts a particularly intriguing methodological spin on the differences between the Blaug view and the Archibald-Hennipman view of Paretian welfare economics.

Archibald's paper was a product of the LSE staff seminar in 'Methodology, Measurement, and Testing' (the $\mathrm{M}^{2} \mathrm{~T}$ seminar) that Richard Lipsey began in 1957 (De Marchi 1988). The seminar was both a product of, and a response to, Robbins's interpretation of economic methodology. As Neil De Marchi explained in his discussion of the methodological impact of the seminar:

This group-really a palace guard, since many had been students under Robbins and owed their elevation to his influence-sought to recast economic knowledge in falsifiable form and proclaim their independence from the dogma, in which they had been schooled, that quantification is not only difficult but unnecessary.

These may sound like sweeping aspirations, but the goal was actually very specific: to replace Robbins's Nature and Significance of Economic Science as the dominant source of methodological ideas for British economists and to argue for the notion that they alone cannot be a sufficient basis for policy conclusions. 
Expressed positively, economics should become a quantified science (De Marchi 1988, 141).

Archibald in particular-who was greatly influenced by Samuelson's Foundations - sought to use Samuelson's analytical framework as the basis for a purely scientific version of the new welfare economics that could restore the field to its respected place within positive economic science after being dethroned by Robbins's arguments against interpersonal utility comparisons. Robbins made a convincing argument that the old welfare economics had no place in economic science, but if the new welfare economics was necessarily normative-as Samuelson and Bergson had argued for welfare economics involving the SWF-then the new welfare economics would be scientifically no better than the old. On the other hand, if Pareto optimality/efficiency and the fundamental theorems did not involve value judgments, then the new welfare economics (at least sans SWF) would have a rightful place along with the rest of positive economic science.

Archibald's argument was wide-ranging, but I will focus on two interrelated points that also show up later in Hennipman's papers. The first is that although economists often talk about welfare economics as if it tells us-or policy makers-what we "ought to do" for the social good, there is nothing about the theory itself that requires, or even suggests, that interpretation. As Archibald put it, his argument

will not satisfy those who, because they demand of welfare economics that it 'tell them what to do', understand by welfare economics a discipline necessarily founded upon value judgments, and therefore assert simply that my use of the term is not theirs (Archibald 1959, 316).

For Archibald, and moving to his second point, welfare economics is really no different than other areas of economics such as consumer choice theory or the theory of the firm. Following Robbins's definition of economics as "the science which studies human behaviour as a relationship between ends and scarce means which have alternative uses" (Robbins 1935 [1932], 16) the economist starts with given wants and then "asks how their progress towards their objectives is conditioned by the scarcity of means" (Robbins 1935 [1932], 24). Welfare economics is just an extension of this inquiry into the question of economic efficiency. A PPI allocation is one in which at least one person could be made better off without making someone else worse off 
and that is an inefficient way of satisfying given wants with the available means. If the first fundamental theorem of welfare economics demonstrates that every $\mathrm{CE}$ is $\mathrm{PO}$, then it shows that competitive markets are an efficient way to satisfy given wants with scarce means. Why should such a theorem have any less cognitive significance than a well-established area within economic science such as consumer choice theory? As Archibald explains, given Robbins's definition, it should not:

[...] it is hard to understand why welfare economics should be set apart. If we enquire into the efficiency of alternative arrangements for satisfying given wants, why is a judgment about these wants a necessary foundation for the theorems we discover? [...] The sensible procedure in welfare economics appears quite simply to be this: we take, as an interesting criterion, the choice-system of the individuals, and ask how different arrangements alter the available choices. That we call the choice-criterion an index of welfare is no value judgment or prescriptive implication (Archibald 1959, 317).

As he summarized the argument: ${ }^{9}$

The enquiries we label "welfare economics" are positive enquiries into the effects on certain indexes of alternative arrangements [...] No value judgments need precede the enquiry; [...] and the conclusions have no prescriptive force. The theorems of welfare economics are thus theorems in positive economics; they are concerned with the relationship between given ends and available means (Archibald 1959, 320).

Hennipman repeats both of Archibald's arguments, but also adds some additional criticisms of-and a new twist on-normative interpretations such as Blaug's. Like Archibald, he admits that economists in fact use welfare economics in normative ways:

The characterization of welfare economics as normative has undoubtedly a considerable descriptive validity. As Blaug points out,

\footnotetext{
${ }^{9}$ One aspect of Archibald's argument that I will not discuss because it would carry us too far a field is his use of a version of revealed preference theory to characterize preference, choice, and welfare. This topic has recently received a lot of attention, in part because of its methodological use by Gul and Pesendorfer (2008), and raises a number of methodological issues well beyond the task at hand. For criticism of Archibald's particular use of revealed preference, see Mongin 2006, 272-275; and for more general discussions of the relationship between contemporary revealed preference theory and welfare economics, see Hands 2012b; and Hausman 2008, 2012. For a discussion of the relationship between Blaug's methodology and Gul and Pesendorfer's position, see Hands 2013.
} 
economists do in fact judge how practical problems concerning allocation should be solved (Hennipman 1992, 434).

Similarly, he explains that the "neutral" interpretation of concepts like economic efficiency is just a particular version of an instrumental approach to finding efficient means for achieving given ends. The choice between the "normativist" and the "neutralist" reading of Pareto optimality is "a free methodological choice" (Hennipman 1992, 434). ${ }^{10}$

The neutral approach takes allocative efficiency as a given end in the sense that it may be a desired objective, without itself endorsing the Paretian value judgments [...]

In consequence, the positive theory does not aim at offering categorical policy prescriptions, it only gives recommendations that are conditional on the acceptance of the postulated goal [...] Propositions of this kind are based on economic judgments [...] which, from the policy point of view, are known as instrumental judgments [...]

This simple scheme definitely refutes the view that welfare economics is necessarily normative because it 'deals with policy' (Hennipman 1992, 429-430).

Hennipman also responds to Blaug's comments on the three assumptions that make Pareto optimality a normative concept (discussed in the previous section) and his remarks are quite similar to those I made above;

Blaug's description of the first and second assumptions makes sense if it is understood as tacitly presupposing that Pareto optimality is an ethical concept and a favoured policy objective [...] however, the third assumption is not 'undeniably' a value judgment (Hennipman 1992, 416).

In addition he criticizes Blaug's presupposition that anything that brings about an increase in welfare is necessarily desirable, by arguing that as a factual matter welfare in economics has traditionally meant just what people prefer (solely the subjective judgment of the individual) and has not been considered desirable in any higher, universal, or objective sense (Hennipman 1992, 420-421).

\footnotetext{
${ }^{10}$ Hennipman also follows Archibald in using the term "essentialism" for the view that welfare economics must necessarily be normative-a pretty damning criticism of a Popperian.
} 
Perhaps Hennipman's most original criticism is a new twist on Blaug's normativity argument. Hennipman criticizes Blaug's view that Pareto optimality is normative because it favors and privileges efficiency over any other standard one might choose to employ in the evaluation of various resource allocations. It becomes not only $a$ normative standard about what ought to be done, but the normative standard.

The real danger of such an effect would arguably arise if, following Blaug, economists were to attach an ethical meaning to efficiency, acclaiming it unreservedly as desirable. This would be most injudicious because while one may regard efficiency in many cases as meritorious, it is not always true that efficiency is "more desirable" than inefficiency. In general its moral value obviously depends on the ends, means and ways of action. One may very well prefer an inefficient to an efficient Gestapo (Hennipman 1992, 422).

Later in the same paper Hennipman offers yet another twist by making the case that since welfare economists must, on his reading of Blaug, know what is ethically good-they must have a "distinctive capability"-and the only "remotely feasible justification" "stems directly from the intrinsic desirability of Pareto optimality" (Hennipman 1992, 435). He then spends five pages criticizing the "normative pretensions" of this "ethical desirability postulate".

Finally, in his reply (1993) to Blaug's (1993) comment on his paper, Hennipman challenges Blaug's notion of methodological value judgments. He accuses Blaug of "semantic novelty" by using, and confusing, two different notions of the normative: ethical and methodological. He argues that Blaug first "defines, in accordance with normal usage, normative as 'involving ethical propositions"” (Hennipman 1993, 291), but then changes to "ought statements" and "appraising judgments" of a methodological sort. For Hennipman this is "sidetracking the debate onto an irrelevant line" which "evades the problem the whole controversy is about, i.e., the ethical commitment of welfare economics" (Hennipman 1993, 292). Hennipman ends his reply with a "dismal epilogue" where he closes with some rather harsh remarks about the "thankless task" of getting Blaug to "see the light" (Hennipman 1993, 294). Needless to say, Hennipman's remarks did not find any common ground with Blaug's position, in fact they seemed to push the two economists farther apart.

Unfortunately, Blaug's comment on Hennipman's 1992 paper was only two and a half pages long and seemed to muddy the waters still 
more. For example, regarding the question of the dual meaning of normative-ethical and methodological-Blaug makes both of the following statements in his brief comment: (i) “Normative' economics, however, involves ethical propositions about what is good or bad which can never be in the nature of the case decisively resolved by factual evidence" (Blaug 1993, 125), and (ii) "But methodological judgments are just as normative as value judgments, that is, facts and more facts can never persuade us to abandon them" (Blaug 1993, 128). I believe I understand what Blaug meant in both of these sentences, but it takes some serious reading between the lines. By "normative economics" in (i), Blaug probably meant "what most economists have traditionally considered normative economics to be", and not "any economics that has a normative component must be ethical", but as I say, it is not entirely clear. It seems that both Hennipman and Blaug are talking at cross purposes and never find any semantic common ground on which they could clearly agree or disagree. One can of course debate whether "the new welfare economics is normative in the sense of necessarily presupposing ethical value judgments" or whether "the new welfare economics is strictly positive in the sense of not presupposing any normative judgments of any type". Either one of these is an interesting and important debate, and one in which many economists would come down on both sides, but an exchange-particularly a heated exchangewhere neither author is clear about which question is being debated is not only one in which nothing will be resolved, it is one in which readers will not even be clear on the positions of the two authors.

Similar remarks can be made for Blaug's discussion of the three value-laden assumptions of Pareto optimality. Regarding (1), that "every individual is the best judge of his or her best interests" (consumer sovereignty), ${ }^{11}$ Blaug says:

The first of these three postulates is clearly a value judgment in the sense that no observations about consumer behaviour could ever force us to abandon the belief that consumers themselves know best what is good for them. Since value judgments belong to normative economics Paretian welfare economics is necessarily normative.

\footnotetext{
${ }^{11}$ Although Blaug and Hennipman agree on very little, they both do seem to believe that "every individual is the best judge of his or her best interest" is equivalent to "consumer sovereignty", which is ironic, since it is not obvious the two terms mean the same thing. The latter seems to mean that the consumer is free to choose, and the former seems to mean that what they choose is always in their best interest; these appear to be entirely different things.
} 
In one sense, this completes, my case and no more need to be said to vindicate my position (Blaug 1993, 125).

Again, this only seems to confuse the issues. If it is possible to get a consensus on what the expression "good for them" means-say increases the survival of the person's genes-then it may in fact be possible to determine whether a particular individual is consuming that which is good for them or not. On the other hand, if one is assuming the good in "good for them" is morally good, but based on subjective personal ethical values, then the problem is methodological; we observe what they consume but we do not have access to their mental states that would allow us to determine whether what they consume matches up with what they think is ethically good. Finally, if one is assuming a universal ethical good in "good for them", then the statement is an ethically normative statement in the sense in which Blaug seems to be using the term "normative economics" a few sentences above this quote. So depending on one's definition of the relevant terms the proposition could be positive, methodologically normative, or ethically normative. It is just not clear.

Similar remarks could be made for his comments on the other two assumptions (2) and (3), but I will not go through the details. The bottom line is that neither Blaug nor Hennipman offered an entirely persuasive defense of their position, and perhaps worse, actually seem to have made the issues, and their positions on the issues, even less clear. If one goes back before this exchange and reads Archibald (1959) and Blaug (1978) one is clear about the two positions; one may agree with one rather than the other, or parts of each, or even support something different than either one, but one understands what the authors are saying about the new welfare economics. After the Hennipman-Blaug debate, that no longer seems to be the case.

\section{WHAT BLAUG MIGHT HAVE SAID TO HENNIPMAN (AND ARCHIBALD)}

In this section, I will try to identify the roots of some of the communication problems in the Blaug-Hennipman debate and also to offer a few arguments that Blaug might have made in response to Hennipman (and in some cases Archibald), but for whatever reason did not make. There are five comments in total, although the first two overlap to some extent. 
1. The term "normative" is the source of much confusion in this exchange and in other discussions of the foundations of welfare economics. Similar remarks can be made about "value judgments", but since the case for "normative" is a bit clearer, I will focus on that. Economists have traditionally equated "normative" with "ethical". As a result of the influence of experimental and behavioral economics, this may currently be changing, but the traditional interpretation of the distinction between "positive" and "normative" in economics has been that positive is about "what is" and normative is about what "ought to be in order to be moral". As Hennipman noted, in the normal usage of economists 'normative' means "involving ethical propositions" (1993, 291). There is a long, as yet unwritten, story about how this came to be within the economics profession, but it is in fact the case, and it leads to numerous confusions. ${ }^{12}$ The source of the problem, as noted briefly above, is that outside of economics, that which is "normative" is necessarily norm-guided, but the norms need not be moral norms. They could be norms of rationality, or epistemology, or many other things, rather than morality. Blaug, with his knowledge of normative philosophy of natural science in general, and his commitment to Popperian scientific norms in particular, recognized that welfare economics could be normative without being ethical, and used this fact in his argument about methodological value judgments. But this use of normative is quite alien to most economists and Hennipman's remarks clearly reflect this. That said, Blaug does not help matters much because he never clearly explains that ethically normative is just one particular instantiation of normative, and often slips into the standard economist usage himself. Some definitional groundwork would have been very useful and it would have decreased the amount of talking at crosspurposes. Blaug's arguments about the role of methodological norms in strictly positive science are sound, but they are never entirely clear because of the blinders imposed by the traditional way the term normative has been used in economics.

2. Following on the previous point, if Blaug had clarified the diversity of ways in which the term 'normative' is used outside of economics, he would have opened the door to an additional argument regarding how a type of (non-ethical) normativity enters into welfare

\footnotetext{
${ }^{12}$ Although, for an excellent beginning on this historical project, see Heukelom 2014. He provides a detailed historical discussion of the differences between economists and experimental psychologists over how 'normative' is interpreted.
} 
economics. Both Archibald and Hennipman argued that talking about an efficient allocation in welfare economics was just like talking about the optimal bundle in consumer choice theory. Rational choice theory in general and consumer choice theory in particular is just an application of instrumental rationality-selecting the most efficient means for achieving any given ends. Their argument was that the new welfare economics was no less scientific, and thus no more normative, than the ordinal utility theory. But why should we think that ordinal utility is itself devoid of normative considerations. Does ordinal utility theory tell us "what is" by empirically discovering the underlying utility functions that cause choice behavior? Perhaps there are some specific approaches-revealed preference or imputed valuation-that try to do this, but this is not standard textbook economics. The preferences and utility functions that drive most exercises in choice theory are not given by nature or by the best available evidence-they are posited-and the theoretical exercise simply draws out the deductive implications of that posit. Most of the "given" wants of economics are posited wants rather than found wants, and they are not just any-old posited wants. They are posited rational wants. They are wants embodied in well-behaved, complete and transitive, preferences with sufficient structure to support the existence of an ordinal utility function defined over the entire choice space. So where do these posited restrictions come form? They involve rationality. The posited rational wants are motivated by our normative value judgments about what one "ought to do in order to be rational". There is a reason that many elementary textbooks call the transitivity assumption "rationality"-it originates in our normative intuitions about the essential nature of rationality. This makes the rational choice foundations of welfare economics, and thus welfare economics, laden with normativity. ${ }^{13}$ They are norms of rationality not morality, and the presence of such normative influence does not prevent the resulting economic theory from being scientifically adequate, but they are norms nonetheless. This is not going to win over those-perhaps like Hennipman-who only want to debate the question of whether the new welfare economics is ethically normative, but it seems to be a nice way to make Blaug's point that the new welfare economics is not strictly positive in the way that Archibald, Hennipman, and others have argued.

\footnotetext{
${ }^{13}$ A related argument about rationality and normativity in choice theory is given in Hausman and McPherson 2006.
} 
3. One simple thing that would clarify the discussion would be to decide what "welfare economics" is, before entering into a debate about whether it is normative or positive. It seems that the different economists discussed above have quite different definitions. For Archibald and Hennipman it seems that welfare economics is about labeling various resource allocations as efficient or inefficient. The theory says " $\mathrm{X}$ is an efficient allocation" (in the world or in a model) and that is the end of it. Nothing else seems to follow from the fact that an allocation is so labeled. It does not necessarily say that it is better than other allocations, or that the government or anyone else should try to bring $\mathrm{X}$ about. Of course they consistently note that adding extra normative judgments about efficient allocations is always permissible, but they are not necessary implications of the analysis-and it is still "welfare economics" even if no such additional normative structure is added. Although it is not entirely clear how Bergson or Samuelson would view the act of labeling efficient allocations, it is clear that just doing so would not be welfare economics; for them welfare economics involves the interpersonal utility comparisons provided by a SWF. Unlike Archibald and Hennipman, Blaug obviously defines welfare economics in the traditional way as the microeconomic theory that provides tools for the evaluation of various economic policies, institutional arrangements, and the allocation of economic resources. And although Blaug's definition is more consistent with professional practice, it is not necessary to decide which definition is more descriptively accurate. The issue is simply that before one is involved in a debate over whether the new welfare economics is necessarily normative it would be useful to agree on what welfare economics is (in addition to, as noted above, what normative means).

4. Blaug should have responded to Hennipman's claim that by making Pareto optimality (ethically) normative, Blaug committed all economists to this, and only this, notion of the good or what the society ought to do. This is, well, silly. Pointing out that Pareto optimality involves ethical values only draws attention to the fact that ethical values are involved, and then once recognized, the door is open to consideration of other possible ethical values. ${ }^{14}$ Blaug is not saying that Pareto optimality entails the universal notion of what is good; he is

\footnotetext{
${ }^{14}$ I would note this is the general approach of Hausman and McPherson (2006).
} 
simply saying that it entails some notion of the good (basically that the satisfaction of individual preferences is good), and by implication other ethical judgments might be considered. This is a very weak argument by Hennipman and Blaug should have pointed it out in his comment.

5. Finally, I close by returning to the founders of the new welfare economics: Bergson and Samuelson. It seems fairly easy to reconcile Blaug's view with the views of these founders. After all, they too define welfare economics in terms of the evaluation of policies and institutions, they just do not consider the mere mention of Pareto optimality to be sufficient to make a particular piece of economic analysis into welfare economics. A particular piece of theorizing becomes welfare economics when one adds a SWF: a value judgment that such allocations are a good thing and can be used to defend policies on that basis. Although Bergson and Samuelson are silent about the question of non-ethical normative judgments such as rationality in their writings on the new welfare economics, one could certainly add such non-ethical normativity to their general framework. One could argue, consistent with the case that Blaug seems to want to make, that welfare economics is not strictly positive because the choice theory on which welfare economics rests is laden with normative notions of rationality. This would take care of Blaug's problem about "the quaint notion of the 'new' welfare economics that propositions about 'efficiency' are somehow value-free, while propositions about 'equity' are necessarily value laden" (Blaug 1978, 626), without committing the basic technical machinery of welfare economics or the fundamental theorems to the charge of being ethically normative. The theorems, as in the view of Archibald and Hennipman, would be methodologically just like consumer choice theory, it is just that it too involves normative-though not ethical-considerations about what one ought to do in order to be rational. Then when one moves beyond the background theoretical machinery to real welfare economics-that which judges institutions and suggests policy-here the ethical considerations would be explicit (and necessary). The new welfare economics-defined as welfare economics has traditionally been defined-would in fact (necessarily) involve ethical value judgments as argued by Bergson, Samuelson, and Blaug. This seems to answer Blaug's main concerns and make his most important points, and it does so without contradicting anything in the stated positions of either Bergson or Samuelson. 


\section{CONCLUSION}

This paper has tried to clarify the various points of view in the long-standing debate over the normative character of the new welfare economics: in general and with particular reference to Blaug's debate with Hennipman. The original interpretation of Bergson and Samuelson, as well as the strictly positive interpretation of Archibald and Hennipman, were examined in detail. The exchange between Blaug and Hennipman was also discussed in detail, but a conclusive assessment was not reached because there was such a lack of agreement about the starting point, purpose of the debate, and even the relevant definitions, that both authors ended up often talking past, rather than seriously addressing, the arguments of the other economist. Finally, in section three, five additional points were made to help explain some of the sources of confusion in the debate and also to offer a few arguments that Blaug might have made in his exchange with Hennipman and discussion of Archibald.

\section{REFERENCES}

Archibald, G. C. 1959. Welfare economics, ethics, and essentialism. Economica, 26 (104): 316-327.

Bergson, Abram. 1938. A reformulation of certain aspects of welfare economics. The Quarterly Journal of Economics, 52 (2): 310-334.

Bergson, Abram. 1954. On the concept of social welfare. The Quarterly Journal of Economics, 68 (2): 233-252.

Blaug, Mark. 1976. Kuhn versus Lakatos, or paradigm versus research programmes in the history of economics. In Method and appraisal in economics, ed. S. J. Latsis. Cambridge: Cambridge University Press, 149-180.

Blaug, Mark. 1987 [1962]. Economic theory in retrospect. Cambridge (UK): Cambridge University Press.

Blaug, Mark. 1990a. Economic theories, true or false?: essays in the history and methodology of economics. Cheltenham (UK): Edward Elgar.

Blaug, Mark. 1990b. Reply to D. Wade Hands's 'Second thoughts on "Second thoughts": reconsidering the Lakatosian progress of The general theory'. Review of Political Economy, 2 (1): 102-104.

Blaug, Mark. 1991. Second thoughts on the Keynesian Revolution. History of Political Economy, 23 (2): 171-192.

Blaug, Mark. 1992 [1980]. The methodology of economics, or how economists explain. Cambridge (UK): Cambridge University Press.

Blaug, Mark. 1993. Pieter Hennipman on Paretian welfare economics: a comment. De Economist, 141 (1): 127-129.

Blaug, Mark. 1998. The positive-normative distinction. In The handbook of economic methodology, eds. J. B. Davis, D. W. Hands, and U. Mäki. Cheltenham (UK): Edward Elgar, 370-374. 
Blaug, Mark. 2007. The fundamental theorems of modern welfare economics, historically contemplated. History of Political Economy, 39 (2): 185-207.

Cooter, Robert, and Peter Rappoport. 1984. Were the ordinalists wrong about welfare economics? Journal of Economic Literature, 22 (2): 507-530.

Cooter, Robert, and Peter Rappoport. 1985. Reply to I. M. D. Little's comment. Journal of Economic Literature, 23 (3): 1189-1191.

Davis, John B. 1990. Cooter and Rappoport on the normative. Economics and Philosophy, 6 (1): 139-146.

De Marchi, Neil. 1988. Popper and the LSE economists. In The Popperian legacy in economics, ed. Neil De Marchi. Cambridge: Cambridge University Press, 139-166.

Friedman, Milton. 1953. The methodology of positive economics. In Essays in positive economics. Chicago: University of Chicago Press, 3-43.

Graaff, J. de V. 1968 [1957]. Theoretical welfare economics. Cambridge: Cambridge University Press.

Gul, Faruk, and Wolfgang Pesendorfer. 2008. The case for mindless economics. In The foundations of positive and normative economics: a handbook, eds. A. Caplin, and A. Schotter. Oxford: Oxford University Press, 3-39.

Hands, D. Wade. 1984. Blaug's economic methodology. Philosophy of the Social Sciences, 14 (1): 115-125.

Hands, D. Wade. 1990. Second thoughts on 'Second thoughts': reconsidering the Lakatosian progress of The general theory. Review of Political Economy, 2 (1): 6981.

Hands, D. Wade. 2009. Effective tension in Robbins' economic methodology. Economica, 76 (1): 831-844.

Hands, D. Wade. 2010. Economics, psychology, and the history of consumer choice theory. Cambridge Journal of Economics, 34 (4): 633-648.

Hands, D. Wade. 2012a. The positive-normative dichotomy and economics. In Philosophy of economics, ed. Uskali Mäki; vol. 13 of Handbook of the philosophy of science, eds. D. Gabbay, P. Thagard, and J. Woods. Amsterdam: Elsevier, 219-240.

Hands, D. Wade. 2012b. Foundations of contemporary revealed preference theory. Erkenntnis, 78 (5): 1081-1108.

Hands, D. Wade. 2013. GP08 is the new F53: Gul and Pesendorfer's methodological essay from the viewpoint of Blaug's Popperian methodology. In Mark Blaug: rebel with many causes, eds. Marcel Boumans, and Matthias Klaes. Cheltenham (UK): Edward Elgar, 245-265.

Hausman, Daniel. 2008. Mindless or mindful economics: a methodological evaluation. In The foundations of positive and normative economics: a handbook, eds. A. Caplin, and A. Schotter. Oxford: Oxford University Press, 125-151.

Hausman, Daniel. 2012. Preference, value, choice, and welfare. Cambridge: Cambridge University Press.

Hausman, Daniel M., and Michael S. McPherson. 2006 [1996]. Economic analysis, moral philosophy, and public policy. Cambridge: Cambridge University Press.

Hennipman, Pieter. 1987. A tale of two schools: comments on a new view of the ordinal revolution. De Economist, 135 (2): 141-162.

Hennipman, Pieter. 1992. The reasoning of a great methodologist: Mark Blaug on the nature of Paretian welfare economics. De Economist, 140 (4): 413-445. 
Hennipman, Pieter. 1993. Moving in circles: Blaug once again on the nature of Paretian welfare economics. De Economist, 141 (2): 290-294.

Heukelom, Floris. 2014. Behavioral economics: a history. Cambridge: Cambridge University Press.

Lange, Oscar. 1942. The foundations of welfare economics. Econometrica, 10 (3/4): 215-228.

Little, Ian M. D. 2002 [1950]. A critique of welfare economics. Oxford: Oxford University Press.

Little, Ian M. D. 1985. Robert Cooter and Peter Rappoport, "Were the ordinalists wrong about welfare economics?": a comment. Journal of Economic Literature, 23 (3): 1186-1188.

Mongin, Philippe. 2006. Value judgments and value neutrality in economics. Economica, 73 (290): 257-286.

Myint, Hla. 1965 [1948]. Theories of welfare economics. New York: Augustus M. Kelley.

Robbins, Lionel. 1935 [1932]. An essay on the nature and significance of economic science. London: Macmillan \& Co.

Samuelson, Paul A. 1947. Foundations of economic analysis. Cambridge (MA): Harvard University Press.

Samuelson, Paul A. 1952. Comment on welfare economics. In A survey of contemporary welfare economics, ed. B. F. Haley. Homewood (IL): Richard D. Irwin [Reprinted in The collected scientific papers of Paul A. Samuelson, volume II, ed. Joseph E. Stiglitz. Cambridge (MA): MIT Press, 1102-1104].

Samuelson, Paul A. 1977. When it is ethically optimal to allocate money income in stipulated fractional shares. In Natural resources, uncertainty, and general equilibrium systems: essays in memory of Rafael Lusky, eds. A. S. Blinder, and P. Friedman. New York: Academic Press [Reprinted in The collected scientific papers of Paul A. Samuelson, volume V, ed. Kate Crowley. Cambridge (MA): MIT Press, 55-75].

Samuelson, Paul A. 1981. Bergsonian welfare economics. In Economic welfare and the economics of Soviet socialism: essays in honor of Abram Bergson, ed. S. Rosefielde. Cambridge (UK): Cambridge University Press [Reprinted in The collected scientific papers of Paul A. Samuelson, volume V, ed. Kate Crowley. Cambridge (MA): MIT Press, 3-46].

D. Wade Hands is distinguished professor of economics at the University of Puget Sound in Washington state and has taught history of economic thought for over thirty years. He has written on a wide range of topics in the history of economic thought and economic methodology. He is co-editor of The Journal of Economic Methodology and the author of Reflection without rules: economic methodology and contemporary science theory (Cambridge University Press, 2001). His Agreement on demand: consumer choice theory in the 20th century, edited with Philip Mirowski, was published in 2006 by Duke University Press and The Elgar companion to recent economic methodology, edited with John B. Davis, was published in 2011. Contact e-mail: <hands@pugetsound.edu> 